\title{
The importance of participating in the Brazilian Association of Pharmaceutical Sciences
}

Over the past years, Brazilian scientists in fields broadly related to Pharmaceutical Sciences have been discussing the need for an Association to strengthen their representation among funding agencies and policy makers. This need motivated the collaborative work of investigators of the field from all over the country to establish the Brazilian Association for Pharmaceutical Sciences ("Associação Brasileira de Ciências Farmacêuticas, ABCF") in 2003, during the 4th International Congress of Pharmaceutical Sciences in Ribeirão Preto. Since then, members of ABCF have been investing their time and efforts towards the growth, recognition and consolidation of the Association.

$\mathrm{ABCF}$ has been participating and supporting a number of national and international events. In February 2010, we co-supported the School in Pharmacognosy ("Escola de Verão em Farmacognosia"), held in Florianópolis. In July, ABCF will be one of the scientific associations to support the Annual Meeting of the Brazilian Society for Advancement of Sciences (SBPC). Later in the year, we will take part in the Scientific Committee of the Symposium of Medicinal Plants, to be held in September, in João Pessoa. In addition, we are one of the Associations taking part of the FIP Pharmaceutical Sciences 2010 World Congress, to be held in New Orleans, USA, in November. Plans for next year include the co-organization of the 8th International Congress of Pharmaceutical Sciences ('CIFARP'). These are very exciting and busy times!

Another goal of $\mathrm{ABCF}$ is to engage members in the process of selecting representatives for governmental institutes and programs. Our members have been recently invited to recommend representatives for the Pharmaceutical Sciences Review Committee of CNPq ( 'Comitê Assessor de Farmácia do CNPq'). This initiative was aimed at increasing the transparency of the selection process and the awareness of our members regarding their vital role in promoting the pharmaceutical field in Brazil. 


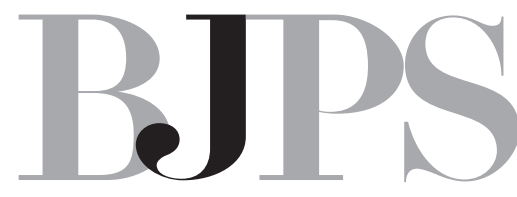

Brazilian Journal of Pharmaceutical Sciences

BRAZILIAN JOURNAL OF PHARMACEUTICAL SCIENCES

The mission of the ABCF is to promote the continuing growth of the Pharmaceutical Sciences in Brazil while contributing to the economic, scientific and technological development of the Country. This mission can only be accomplished with the active participation of our members!

João Luis Callegari Lopes

President of $\mathrm{ABCF}$ 